\title{
Speed and Profile of the Arterial Peripheral Chemoreceptors as Measured by Ventilatory Changes in Preterm Infants
}

\author{
RUBEN E. ALVARO, ZALMAN WEINTRAUB, KIM KWIATKOWSKI, DONALD B. CATES, AND \\ HENRIQUE RIGATTO \\ Departments of Pediatrics, Physiology and Reproductive Medicine, The University of Manitoba, Winnipeg, \\ Manitoba R3E 0L8, Canada
}

\begin{abstract}
To measure the response time of the peripheral chemoreceptors, we studied 13 preterm infants [birth weight $1602 \pm 230 \mathrm{~g}$ (mean $\pm \mathrm{SEM}$ ); gestational age 31 \pm 1 wk; postnatal age $15 \pm 1 \mathrm{~d}$ l during inhalation of $21 \%$ $\mathrm{O}_{2}(15 \pm 5 \mathrm{~s})$ followed by $100 \% \mathrm{O}_{2}(1 \mathrm{~min})$. We used a flow-through system to measure ventilation and gas analyzers to measure alveolar gases. Hypoventilation was observed at 3.6 $\pm 0.6 \mathrm{~s}$ and was maximal at $6.8 \pm 1 \mathrm{~s}$ after $\mathrm{O}_{2}$ began. This maximal response was always associated with an apnea $(>3 \mathrm{~s})$. Alveolar $\mathrm{PO}_{2}$ increased from $13.5 \pm$ $0.1 \mathrm{kPa}(101 \pm 0.8$ torr) (control) to $28.0 \pm 1.2 \mathrm{kPa}(210$ \pm 9 torr) (1st $\mathrm{O}_{2}$ breath), to $42.0 \pm 2.4 \mathrm{kPa}(315 \pm 18$ torr) (1st hypoventilation), to $45.9 \pm 4.1 \mathrm{kPa}(344 \pm 31$ torr) (breath preceding maximal response), and to $53.6 \pm$ $4.1 \mathrm{kPa}(402 \pm 31$ torr) (at maximal response). Minute ventilation was $0.192 \pm 0.011$ (control), $0.188 \pm 0.011$ (1st $\mathrm{O}_{2}$ breath), $0.088 \pm 0.016$ (1st hypoventilation; $p<$ 0.0001 ), $0.122 \pm 0.016$ (breath preceding maximal response; $p<0.0002$ ), and $0.044 \pm 0.011 \mathrm{~L} / \mathrm{min} / \mathrm{kg}$ at maximal response $(p<0.0001)$. This decrease in ventilation was due to a decrease in frequency with no appreciable change in tidal volume. The initial period of hypoventilation $(19 \pm 4 \mathrm{~s})$ was followed by a breathing interval $(10 \pm 2 \mathrm{~s})$ and a second period of hypoventilation (14 \pm 3 s) before continuous breathing resumed. These findings suggest that the peripheral chemoreceptors in these infants have a high baseline activity and a fast response time. (Pediatr Res 32: 226-229, 1992)
\end{abstract}

Previous studies in preterm infants have shown that there is an immediate decrease followed by an increase in ventilation in response to inhalation of $100 \% \mathrm{O}_{2}(1-4)$. This immediate decrease in ventilation, usually associated with apnea, is traditionally attributed to the effect of $\mathrm{O}_{2}$ on the peripheral chemoreceptors, producing what Julius Comroe (5) used to call the physiologic denervation of the peripheral chemoreceptors.

Because of the sharp breathing response to inhaled $\mathrm{O}_{2}$ in these infants, we thought we could measure the response time of the peripheral chemoreceptors. Therefore, the purpose of our study was to test the hypothesis that the speed of the peripheral

Received November 5, 1991; accepted March 18, 1992.

Correspondence: Henrique Rigatto, M.D., Neonatal Research, RM WR 125 Women's Hospital, 735 Notre Dame Avenue, Winnipeg, Manitoba, Canada R3E 0L8.

Supported by the Medical Research Council of Canada, Grant MT-4980, and the Children's Hospital of Winnipeg Research Foundation.

${ }^{1}$ Presented in part at the meeting of the Federation of American Societies for Experimental Biology, Washington, DC, April 1-5, 1990 and at the meeting of the Society for Pediatric Research, Anaheim, CA, May 7-11, 1990. chemoreceptor response could be determined in "healthy" preterm infants by measuring the changes in ventilation induced by inhalation of $100 \% \mathrm{O}_{2}$.

\section{MATERIALS AND METHODS}

Subjects. We studied 13 healthy preterm infants with a birth weight of $1602 \pm 230 \mathrm{~g}$ (mean \pm SEM), a study weight of 1652 $\pm 260 \mathrm{~g}$, a gestational age of $31 \pm 1 \mathrm{wk}$, and a postnatal age of $15 \pm 1 \mathrm{~d}$. The study was approved by the faculty committee on the use of human subjects in research, University of Manitoba, and written parental consent was obtained from one of the parents.

Methods. We have previously described the system to measure ventilation $(6,7)$. Briefly, we used a nosepiece and a screen flowmeter to measure respiratory minute volume and alveolar gases. We used a constant background flow ( $3 \mathrm{~L} / \mathrm{min})$ to eliminate valves and to reduce dead space. The infant breathed through the nostril adapters and added to (expiration) or subtracted (inspiration) flow from the background flow. This background flow was electrically balanced to an artificial zero.

We monitored breath-to-breath alveolar $\mathrm{PO}_{2}$ and $\mathrm{PCO}_{2}$ using Beckman analyzers. The $95 \%$ rise times of the analyzers were 0.16 and $0.18 \mathrm{~s}$ for $\mathrm{CO}_{2}$ and $\mathrm{O}_{2}$, respectively. The EEG was monitored using a single channel with an electrode placed in the right frontal position and referenced to the left mastoid. The electrooculogram was recorded from eye electrodes referenced to the right ear. Oxygen saturations and ECG were used to monitor the infant's well-being but not as an end point of this study. Sleep state was monitored according to previous criteria (4). All variables were recorded on a polygraph (model 4221, Nihon Kohden, Tokyo, Japan).

Procedure. Infants were studied on the Ohio Neonatal Intensive Care Unit (Ohio Medical Products, Madison, WI) in a neutral thermal environment with skin abdominal temperature at $36.5 \pm 0.03^{\circ} \mathrm{C}$. After appropriate placement of the various electrodes and the nosepiece, infants were allowed to sleep. Once they had been in quiet sleep breathing $21 \% \mathrm{O}_{2}$ for $2 \mathrm{~min}, 100 \%$ $\mathrm{O}_{2}$ was given for $1 \mathrm{~min}$. Minute ventilation, tidal volume, frequency, alveolar $\mathrm{PO}_{2}$, alveolar $\mathrm{PCO}_{2}$, inspiratory drive, and the "duty cycle" were measured breath by breath during $21 \% \mathrm{O}_{2}(15$ $\pm 5 \mathrm{~s})$ and during $100 \% \mathrm{O}_{2}(1 \mathrm{~min})$.

Data collection and analysis. We analyzed the records by hand and transferred the data to a computer for appropriate treatment. Control values were taken from the last eight breaths preceding the administration of $\mathrm{O}_{2}$. The speed of the response was measured from the initiation of inspiration immediately after the increase in fraction of inspired $\mathrm{O}_{2}$. We used a paired $t$ test to assess the significance of the differences between control values and those obtained in response to $100 \% \mathrm{O}_{2}$. To find the 1 st breath after $100 \% \mathrm{O}_{2}$ showing hypoventilation, we used a variation of the 

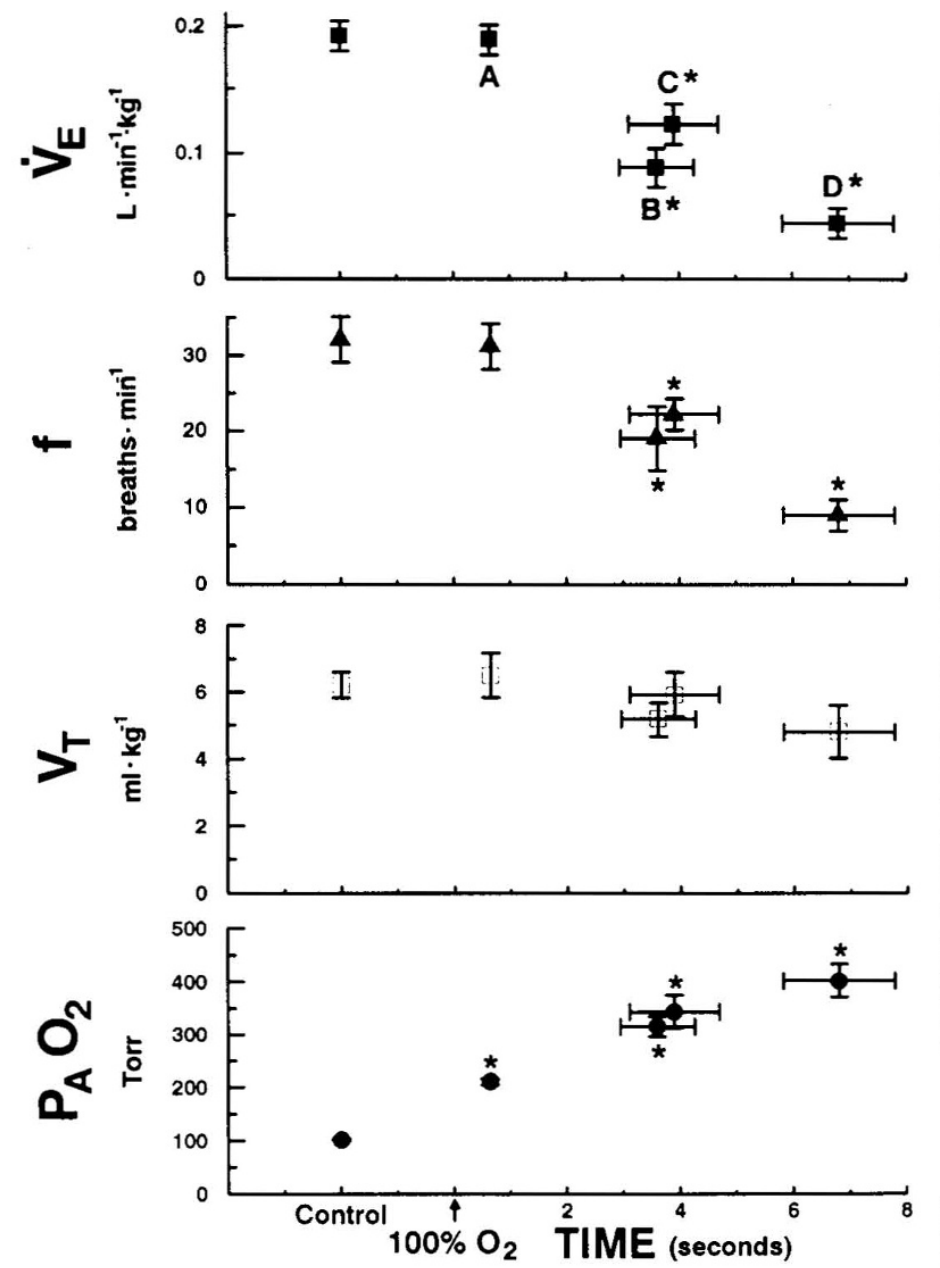

Fig. 1. Changes in ventilatory variables in response to $100 \% \mathrm{O}_{2}$. Hypoventilation occurred shortly after inhalation of $100 \% \mathrm{O}_{2}$ began $(3.6$ $\pm 0.6 \mathrm{~s}$ ) and preceded the maximal response (apnea), which occurred at $6.8 \pm 1 \mathrm{~s}$. Values are mean \pm SEM. $A$, 1st breath in $100 \% \mathrm{O}_{2} ; B, 1$ st breath with hypoventilation; $C$, breath preceding maximal response; $D$, maximal response $(\mathrm{kPa}=$ torr $\times 0.1333)$. $\dot{\mathrm{V}}_{\mathrm{E}}$, minute ventilation; $\mathrm{f}$, frequency; $\mathrm{V}_{\mathrm{T}}$, tidal volume; and $\mathrm{P}_{\mathrm{A}} \mathrm{O}_{2}$, alveolar $\mathrm{PO}_{2}$.

paired $t$ test named "the comparison of a single value into the mean of the sample" (8). Analysis of variance and Fisher's least significant difference test were used to test the significance of the differences among values obtained during each cycle of hypoventilation and breathing observed in most babies after $100 \% \mathrm{O}_{2}$. Results are expressed as mean \pm SEM. A probability value equal to or less than 0.05 was considered significant.

\section{RESULTS}

With inhaled $\mathrm{O}_{2}$, alveolar $\mathrm{PO}_{2}$ increased from $13.5 \pm 0.1 \mathrm{kPa}$ (101 \pm 0.8 torr) (control) to $28.0 \pm 1.2 \mathrm{kPa}(210 \pm 9$ torr) (1st $\mathrm{O}_{2}$ breath), to $42.0 \pm 2.4 \mathrm{kPa}(315 \pm 18$ torr) (1st hypoventilation), to $45.9 \pm 4.1 \mathrm{kPa}$ (344 \pm 31 torr) (breath preceding maximal response), and to $53.6 \pm 4.1 \mathrm{kPa}(402 \pm 31$ torr) (at maximal response) (Fig. 1, Table 1).

The inhalation of $100 \% \mathrm{O}_{2}$ was associated with an immediate decrease in ventilation at $3.6 \pm 0.6 \mathrm{~s}$ (mean \pm SEM) from 0.192 \pm 0.011 (control) to $0.088 \pm 0.016 \mathrm{~L} / \mathrm{min} / \mathrm{kg}$ (1st breath with hypoventilation, $p<0.0001$ ). The maximal response was seen at $6.8 \pm 1 \mathrm{~s}$, with minute ventilation decreasing to $0.044 \pm 0.011$ $\mathrm{L} / \mathrm{min} / \mathrm{kg}(p<0.0001)$ (Fig. 1, Table 1). This decrease in ventilation was due to a decrease in frequency from $32 \pm 3$ (control) to $19 \pm 4$ breath/min (1st breath with hypoventilation; $p<0.0001)$ and to $9 \pm 2$ breath/min at maximal response $(p<$ $0.0001)$. There was no appreciable change in tidal volume (Fig. 1, Table 1). The maximal response was always associated with an apnea $(>3 \mathrm{~s})$. This initial hypoventilation had a duration of $19 \pm 4 \mathrm{~s}$. It was followed by a breathing interval of $10 \pm 2 \mathrm{~s}$ and a second apnea or hypoventilation of $14 \pm 3 \mathrm{~s}$ before continuous breathing resumed (Figs. 2 and 3 ). The two periods of hypoventilation were significantly different from control and the two recovery periods $(p<0.05)$. This was due to a decrease in frequency with no change in tidal volume. The inspiratory drive did not change during the period leading to maximal hypoventilation and the duty cycle decreased as a consequence of an increase in expiratory time (Table 1). The increase in alveolar $\mathrm{PO}_{2}$ was fast, reaching levels of about $27 \mathrm{kPa}$ (200 torr) during the first $2 \mathrm{~s}$ of $100 \% \mathrm{O}_{2}$ (Fig. 1).

\section{DISCUSSION}

We found that the decrease in ventilation with $100 \% \mathrm{O}_{2}$ was very fast, occurring within the first three breaths after $100 \% \mathrm{O}_{2}$ began. This decrease in ventilation was related to a decrease in frequency with no appreciable change in tidal volume. The maximal response (maximal hypoventilation) was always associated with an apnea $(>3 \mathrm{~s})$, which was followed by a breathing interval and a second period of hypoventilation or apnea before continuous breathing resumed. The sharp response to $\mathrm{O}_{2}$ in these infants reflects a high baseline activity of the peripheral chemoreceptors, likely related to the relatively low arterial $\mathrm{PO}_{2}$ known to be present in these infants (7). This high baseline firing of the peripheral chemoreceptors is abolished when arterial $\mathrm{PO}_{2}$ increases after $100 \% \mathrm{O}_{2}$, eliminating the hypoxic drive from the chemoreceptors, with a consequent sharp decrease in ventilation $(1,2,7)$.

Studies done in anesthetized cats, dogs, and rabbits measuring the ventilatory response to inhalation of $100 \% \mathrm{O}_{2}$ have shown an almost instantaneous reduction of the respiratory frequency and tidal volume after $\mathrm{O}_{2}$ was given. Denervation of the sinus region abolished this response (9-11). Direct recording from a

Table 1. Physiologic measurements in response to $100 \% \mathrm{O}_{2}$ (mean $\left.\pm S E M\right)^{*}$

\begin{tabular}{|c|c|c|c|c|c|c|c|c|}
\hline \multirow{2}{*}{$\begin{array}{l}\text { Experimental condi- } \\
\text { tions }\end{array}$} & \multirow{2}{*}{$\begin{array}{c}\dot{\mathrm{V}}_{\mathrm{E}}(\mathrm{L} \cdot \min \\
\left.\mathrm{kg}^{-1}\right)\end{array}$} & \multirow{2}{*}{$\begin{array}{c}\mathrm{f} \text { (breaths. } \\
\min ^{-1} \text { ) }\end{array}$} & \multirow{2}{*}{$\begin{array}{c}\mathrm{V}_{\mathrm{T}}(\mathrm{mL} \\
\left.\mathrm{kg}^{-1}\right)\end{array}$} & \multicolumn{2}{|c|}{$\mathrm{P}_{\mathrm{A}} \mathrm{O}_{2}$} & \multirow{2}{*}{$\begin{array}{c}\mathrm{V}_{\mathrm{T}} / \mathrm{T}_{\mathrm{i}} \\
\left(\mathrm{mL} \cdot \mathrm{s}^{-1}\right)\end{array}$} & \multirow[b]{2}{*}{$\mathrm{T}_{\mathrm{i}} / \mathrm{T}_{\text {Tот }}$} & \multirow[b]{2}{*}{$\% \Delta \dot{\mathrm{V}}_{\mathrm{E}}$} \\
\hline & & & & $\mathrm{kPa}$ & torr & & & \\
\hline Control & $0.192 \pm 0.011$ & $32 \pm 3$ & $6.2 \pm 0.4$ & $13.5 \pm 0.1$ & $101 \pm 1$ & $10.0 \pm 0.7$ & $0.345 \pm 0.022$ & \\
\hline $\begin{array}{l}1 \text { st breath in } 100 \% \\
\mathrm{O}_{2}\end{array}$ & $0.188 \pm 0.011$ & $31 \pm 3$ & $6.5 \pm$ & $28.0 \pm 1.2 \dagger$ & $210 \pm 9 \dagger$ & $11.2 \pm 1.1$ & $0.310 \pm 0.030$ & -2 \\
\hline $\begin{array}{l}\text { 1 st breath with hypo- } \\
\text { ventilation }\end{array}$ & $0.088 \pm 0.016 \dagger$ & $19 \pm 4 \dagger$ & $5.2 \pm 0.5$ & $42.0 \pm 2.4 \dagger$ & $315 \pm 18 \dagger$ & $8.9 \pm 1.0$ & $0.172 \pm 0.027 \dagger$ & $-54 \dagger$ \\
\hline $\begin{array}{l}\text { Breath preceding } \\
\text { maximal response }\end{array}$ & $0.122 \pm 0.016 \dagger$ & $22 \pm 2 \dagger$ & $5.9 \pm 0.7$ & $45.9 \pm 4.1 \dagger$ & $344 \pm 31 \dagger$ & $10.0 \pm 1.1$ & $0.214 \pm 0.026 \dagger$ & $-37 \dagger$ \\
\hline Maximal response & $0.044 \pm 0.011 \dagger$ & $9 \pm 2 \dagger$ & $4.8 \pm 0.8$ & $53.6 \pm 4.1 \dagger$ & $402 \pm 31 \dagger$ & $38.7 \pm 1.4$ & $0.095 \pm 0.022 \dagger$ & $-77 \dagger$ \\
\hline
\end{tabular}

$* \dot{\mathrm{V}}_{\mathrm{E}}$, minute ventilation; $\mathrm{f}$, frequency; $\mathrm{V}_{\mathrm{T}}$, tidal volume; $\mathrm{P}_{\mathrm{A}} \mathrm{O}_{2}$, alveolar $\mathrm{PO}_{2} ; \mathrm{V}_{\mathrm{T}} / \mathrm{T}_{\mathrm{i}}$, inspiratory drive; $\mathrm{T}_{\mathrm{i}} / \mathrm{T}_{\mathrm{Tor}}$, duty cycle; and \% $\Delta \dot{\mathrm{V}}_{\mathrm{E}}, \%$ change in minute ventilation.

$\dagger p \leq 0.0005$ in relation to control values. 


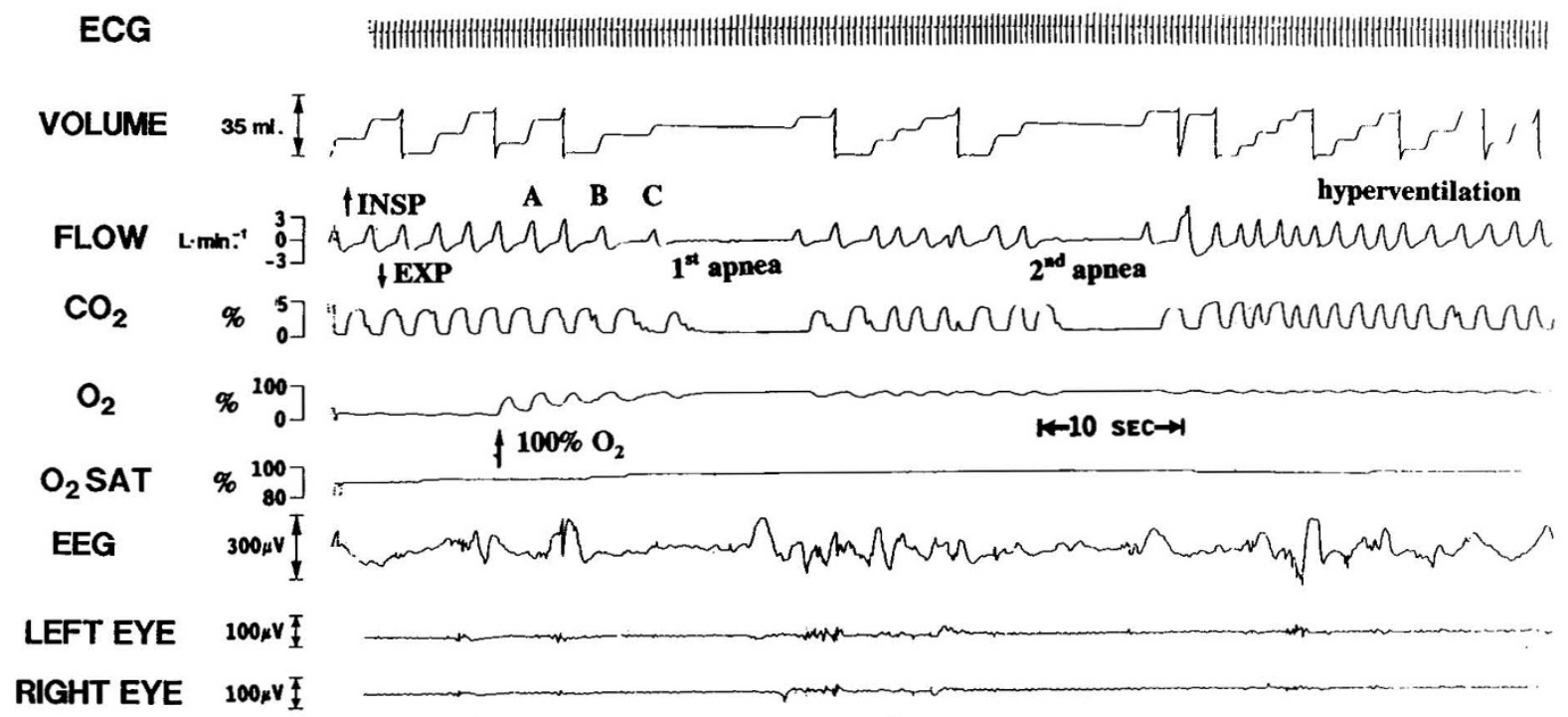

Fig. 2. Representative tracing during quiet sleep. Note the progressive decrease in respiratory frequency with $100 \% \mathrm{O}_{2}$ leading to the first apnea, which was followed by a breathing interval and a second apnea before regular breathing resumed. $A$, First breath in $100 \% \mathrm{O}_{2} ; B$, first breath with hypoventilation and breath preceding maximal response; and $C$, maximal response. $\mathrm{O}_{2} \mathrm{SAT}, \mathrm{O}_{2}$ saturation.
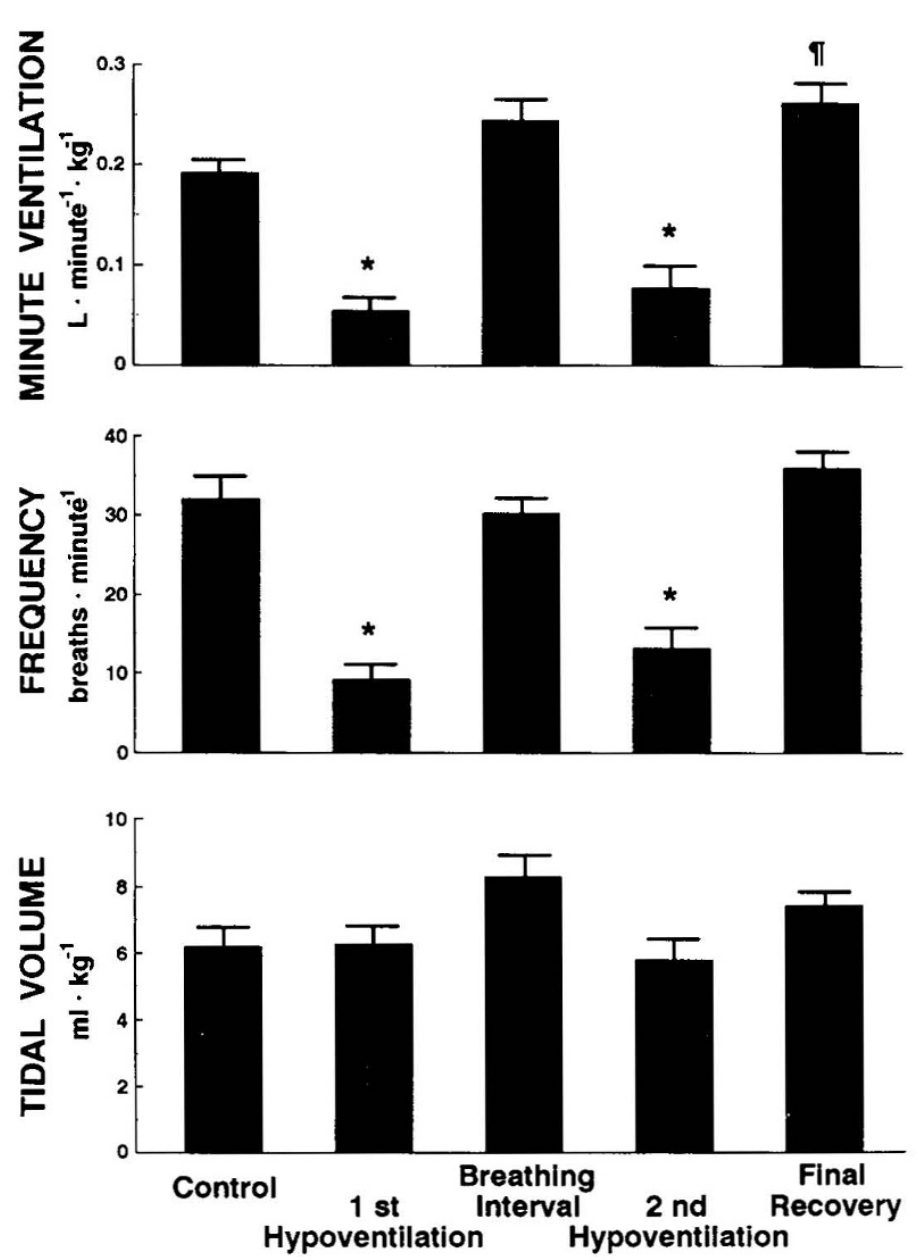

Fig. 3. The first decrease in ventilation was followed by a short recovery and a second decrease in ventilation (2nd hypoventilation) before regular breathing resumed. Values are mean \pm SEM for each event. ${ }^{*}, p<0.05$ compared with control and the two breathing intervals; I, $p<0.05$ compared with control. single chemoreceptor fiber also showed an immediate (after a few seconds) decrease in the number of nerve impulses per unit of time when the animal was made hyperoxic by breathing pure $\mathrm{O}_{2}(12-14)$. In the present study, the speed of the response $(3.6$ \pm 0.6 and $6.8 \pm 1 \mathrm{~s}$ for the $1 \mathrm{st}$ breath with hypoventilation and maximal response, respectively) was similar to that found by Girard et al. (15) and by Brady et al. (1) in term infants. Brady et al. (1) found the response time in term infants difficult to measure accurately because of lack of abrupt change in ventilation. This was not a problem in preterm infants because the breathing responses were quite abrupt.

The decrease in ventilation with inhaled $\mathrm{O}_{2}$ is related to a primary decrease in frequency in preterm infants $(2-4,16)$. The decrease in frequency is related to apnea, which commonly occurs with $100 \% \mathrm{O}_{2}$. Term infants and adult subjects do not become apneic with high inhaled $\mathrm{O}_{2}$ mixtures, but they change ventilation by primarily decreasing tidal volume $(1,11,17-20)$. This distinct response observed in small babies, although not entirely understood, is likely related to the relatively low arterial $\mathrm{PO}_{2}$ and high chemoreceptor firing in these infants $(1,2,7)$.

The administration of $100 \% \mathrm{O}_{2}$ initiated a characteristic pattern of breathing with alternating apneas and breathing intervals. This was observed in most infants (nine of 13) and mimicked what Haldane called "the hunting of the respiratory centers" (21). The inhaled $\mathrm{O}_{2}$ induces the first apnea. During apnea, arterial $\mathrm{PCO}_{2}$ rises, triggering the resumption of breathing until arterial $\mathrm{PCO}_{2}$ decreases again and the hypoventilation or apnea reappears. This sequence goes on, with apneas successively shorter until continuous or regular breathing resumes. The imbalance of ventilation in this situation appears to be due in great part to the action of $\mathrm{O}_{2}$ at the peripheral chemoreceptors. Oxygen appeared not to affect the inspiratory drive, but it decreased the duty cycle because of a prolonged expiratory time.

In summary, we gave $100 \% \mathrm{O}_{2}$ to preterm infants to breathe to measure the speed and profile of the peripheral chemoreceptor response. With inhaled $\mathrm{O}_{2}$, there was an immediate and sharp decrease in ventilation that is conventionally attributed to a decrease in peripheral chemoreceptor drive. Breathing remained unbalanced for a short period before regular breathing resumed. The response time of the peripheral chemoreceptors was $3.6 \pm$ $0.6 \mathrm{~s}$.

Acknowledgments. The authors thank Paula Baryluk-Raposo, Cam Miron, and Marie Meunier for helping with the typing and preparation of the manuscript. 


\section{REFERENCES}

1. Brady JP, Cotton EC, Tooley WH 1964 Chemoreflexes in the newborn infant: effects of $100 \%$ oxygen on heart rate and ventilation. J Physiol (Lond) $172: 332-340$

2. Cross KW, Oppe TE 1952 The effect on inhalation of high and low concentrations of oxygen on the respiration of the premature infant. J Physiol (Lond) $117: 38-55$

3. Rigatto H, Brady JP, de la Torre Verduzco R 1975 Chemoreceptor reflexes in preterm infants: I. The effect of gestational and postnatal age on ventilatory response to inhalation of $100 \%$ and $15 \%$ oxygen. Pediatrics 55:604-613

4. Rigatto H, Kalapesi Z, Leahy FN, Durand M, MacCallum M, Cates D 1982 Ventilatory response to $100 \%$ and $15 \% \mathrm{O}_{2}$ during wakefulness and sleep in preterm infants. Early Hum Dev 7:1-10

5. Comroe J 1974 Physiology of Respiration. Year Book Medical Publishers, Chicago

6. Rigatto H, Brady JP 1972 A new nosepiece for measuring ventilation in preterm infants. J Appl Physiol 32:423-424

7. Rigatto H, Brady JP 1972 Periodic breathing and apnea in preterm infants. I. Evidence of hypoventilation possibly due to central respiratory depression. Pediatrics 50:202-218

8. Sokal RR, Rohlf FJ 1981 Single classification analysis of variance. In: Biom etry, 2nd Ed. WH Freeman and Co., New York, pp 208-270

9. Hejnerman, E 1943 Influence of oxygen inhalation on the chemoreceptor activity of the sinus region in rabbits. Acta Physiol Scand 6:333-335

10. von Euler US, Liljestrand G 1942 Influence of oxygen inhalation on the chemoreceptor activity of the sinus region. Acta Physiol Scand 4:34-44

11. Watt JG, Dumke PR, Comroe Jr JH 1943 Effects of inhalation of 100 per cent and 14 per cent oxygen upon respiration of unanesthetized dogs before and after chemoreceptor denervation. Am J Physiol 138:610-617

12. Biscoe TJ, Purves MJ, Samson SR 1970 The frequency of nerve impulses in single carotid body chemoreceptor afferent fibers recorded in vivo with intact circulation. J Physiol (Lond) 208:121-131

13. Goodman NW 1974 Some observation on the homogenicity of response of single chemoreceptor flows. Respir Physiol 20:271-281

14. Lahiri S, De Laney RG 1975 Stimulus interaction in the responses of carotid body chemoreceptor single afferent fibers. Respir Physiol 24:249-266

15. Girard F, Lacaisse A, Dejours $P 1960$ Le stimulus $\mathrm{O}_{2}$ ventilatoire a la periode neonatale chez l'homme. J Physiol (Paris) 52:108-109

16. Krauss AN, Tory CA, Brown I, Soodalter T, Auld PAMP 1973 Oxygen chemoreceptors in low birth weight infants. Pediatr Res 7:569-574

17. Brady JP, Ceruti EP 1966 Chemoreceptor reflexes in the newborn infant: effect of varying degrees of hypoxia on heart rate and ventilation in a warm environment. J Physiol (Lond) 184:631-645

18. Cross KW, Warner P 1951 The effect of inhalation of high and low oxygen concentrations of the respiration of the newborn infant. J Physiol (Lond) 114:283-295

19. Dripps RD, Comroe Jr J 1947 The effect of the inhalation of high and low oxygen concentrations on respiration, pulse rate, ballistocardiogram and arterial oxygen saturation (oximeter) of normal individuals. Am J Physiol 149:277-291

20. Hey EN, Lloyd BB, Cunningham DJC, Jukes MGM, Bolton DPG 1966 Effects of various respiratory stimuli on the depth and frequency of breathing in man. Respir Physiol 1:193-205

21. Haldane JS, Priestley JG 1935 Respiration, 2nd Ed. Clarendon Press, Oxford, UK 